\title{
Incidents and Accidents: The Way of the Single Event Tester
}

\author{
Kenneth A. LaBel \\ Co- Manager, \\ NASA Electronic Parts and Packaging (NEPP) Program \\ NASA/GSFC \\ ken.label@nasa.gov \\ 301-286-9936 \\ http://nepp.nasa.gov
}




\section{Acronyms}

- command and data handling (C\&DH)

- Crocker Nuclear Laboratory (CNL)

- fiber optic (FO)

- filed programmable gate array (FPGA)

- linear energy transfer (LET)

- National Aeronautics and Space Administration (NASA)

- NASA Electronic Parts and Packaging (NEPP) Program

- Naval Research Laboatory (NRL)

- single event effect (SEE) 


\section{Abstract}

- When performing a single event effect (SEE) test during a test campaign, flexibility and out of the box thinking is often required for unexpected and unplanned events.

- Terminology

- Incidents are events that occur during testing while performing according to the test plan or standard, but are not expected.

- A simple example might be a destructive condition on a technology where none was expected.

- Accidents are events that occur during testing when an unplanned test condition is used and an unexpected result is observed.

- Simple test condition examples might include changing voltage levels or operating frequency. 


\section{An Incident}

- Once upon a time there was a fledging field programmable gate array (FPGA) called the Actel 1280.

- It was a lovely little FPGA and was the first non-volatile that had both combinatorial and sequential logic design options

- A customer hired my group to heavy ion test this device

- Pop! A destructive event occurred unlike latchup

- Ken and his merry band of engineers caucused in the ready room

- "Hmmm. Looks much like a gate rupture. We should change ions to reduce the linear energy transfer (LET) and investigate further."

- Upon returning to the test area: Surprise! The customer was dismounting his parts from the chamber and stated:

- "You must be doing something wrong. l'm taking these parts and giving them to XXX because they don't destroy them the way you do."

- A few months later, the group at XXX discovers dielectric rupture!

- Moral of Story: if it's an unexpected incident, it's worth verifying that it's real instead of assuming it's not. 


\section{And an accident...}

- Back in the good old days of 1990 (I hope all of you can remember that far back!), the first generation of fiber optic (FO) databusses was being developed for space

- NASA, the Naval Research Laboratory (NRL), and others were working together to understand the radiation issues involved with $\mathrm{FO}$ device reliability

- I was a command and data handling (C\&DH) guy just starting to learn radiation effects at that point, but VERY luckily the good Drs. Marshall were at NRL and led the investigation

- We understood going in that the devices would upset with protons - after all, they are "radiation" detectors (light) 


\section{The Accident}

- While testing at Crocker Nuclear Laboratory (CNL), I innocently asked: what happens if we tilt the device (photodiode) along grazing angle?

- BINGO! Proton direct ionization.

- Long term: this discovery brought new concepts to performing rate prediction, eventually leading to physics-based Monte Carlo analysis tools

Energy and angular proton effects in an optocoupler an indication of direct ionization

Kenneth A. LaBel, et al, "SEDS* MIL-STD-1773 Fiber Optic Data Bus: Proton Irradiation Test Results and Spaceflight SEU Data,"

IEEE Transactions on Nuclear Science, Vol. 40, No 6, pp. 1638-1644, Dec. 1993

* = Small Explorer Data Bus

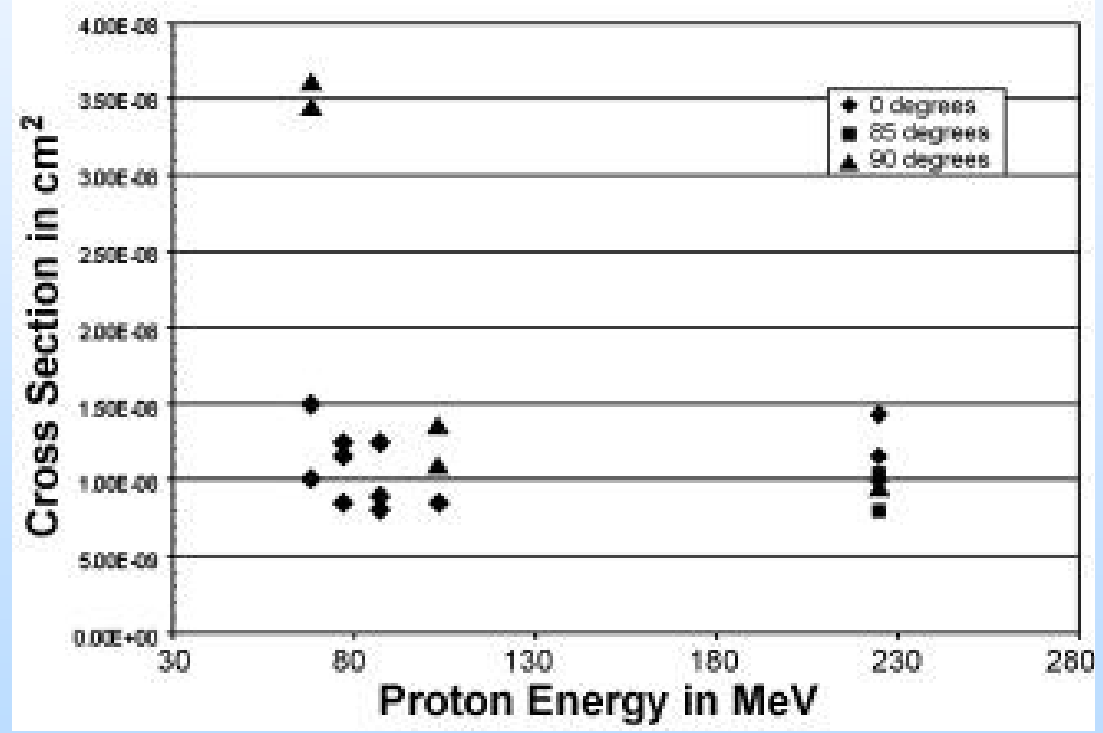

- Moral of Story: Unplanned test conditions sometimes lead to new discoveries. It pays to think beyond the standard approaches at times. 


\section{Discussion}

- Standards and test plans are ALWAYS good starting points, but modern (especially complex) devices often exhibit unexpected results

- Challenges that force you to think and not just do abound

- Consider for example

- Angular (grazing tests aren't always possible)

- Physical (geographic particle impingement versus potential number of targets, re: cells)

- Operational (i.e., state-space coverage - temporal particle impingement versus current operation)

- The largest current commercial devices have $\sim 37$ billion transistors and operate at $>1 \mathrm{Ghz}$

- Seriously, how much data and testing would ever be enough? 